DSM-5 and ICD-11 criteria for bipolar disorder: Implications for the prevalence of bipolar disorder and validity of the diagnosis - A narrative review from the ECNP bipolar disorders network

This is the peer reviewed version of the following article:

Original:

Kessing, L.V., Gonzalez-Pinto, A., Fagiolini, A., Bechdolf, A., Reif, A., Yildiz, A., et al. (2021). DSM-5 and ICD-11 criteria for bipolar disorder: Implications for the prevalence of bipolar disorder and validity of the diagnosis - A narrative review from the ECNP bipolar disorders network. EUROPEAN

NEUROPSYCHOPHARMACOLOGY, 47, 54-61 [10.1016/j.euroneuro.2021.01.097].

Availability:

This version is availablehttp://hdl.handle.net/11365/1137956

since 2021-03-31T14:51:11Z

\title{
Published:
}

DOI:10.1016/j.euroneuro.2021.01.097

Terms of use:

Open Access

The terms and conditions for the reuse of this version of the manuscript are specified in the publishing policy. Works made available under a Creative Commons license can be used according to the terms and conditions of said license.

For all terms of use and more information see the publisher's website.

(Article begins on next page) 
REVIEW

\section{DSM-5 and ICD-11 criteria for bipolar disorder: Implications for the prevalence of bipolar disorder and validity of the diagnosis - A narrative review from the ECNP bipolar disorders network}

Lars Vedel Kessing ${ }^{a, *}$, Ana González-Pinto ${ }^{b}$, Andrea Fagiolini $^{c}$, Andreas Bechdolf ${ }^{d}$, Andreas Reif ${ }^{e}$, Ayșegül Yildiz ${ }^{f}$, Bruno Etains, Chantal Henry ${ }^{\mathrm{h}}$, Emanuel Severusi, Eva Z. Reininghaus ${ }^{j}$, Gunnar Morken ${ }^{k}$, Guy M. Goodwin', Jan Scott ${ }^{\mathrm{m}}$, John R. Geddes', Marcella Rietschel ${ }^{\mathrm{n}}$, Mikael Landén ${ }^{\circ}$, Mirko Manchia ${ }^{\mathrm{p}, \mathrm{q}}$, Michael Bauer ${ }^{\mathrm{i}}$, Monica Martinez-Cengotitabengoa ${ }^{r, s}$, Ole A. Andreassen ${ }^{t}$, Philipp Ritter ${ }^{\mathrm{u}}$, Ralph Kupka ${ }^{\mathrm{v}}$, Rasmus W. Licht ${ }^{\mathrm{w}, \mathrm{x}}$, René Ernst Nielsen $^{w, x}$, Thomas G. Schulze ${ }^{y}$, Tomas Hajek ${ }^{z}$,aa, Trine Vik Lagerberg ${ }^{\mathrm{t}}$, Veerle Bergink ${ }^{\mathrm{ab}, \mathrm{ac}}$, Eduard Vieta ${ }^{\text {ad }}$

${ }^{a}$ Copenhagen Affective Disorder research Centre (CADIC), Psychiatric Centre Copenhagen, Department 0 , University Hospital of Copenhagen, Rigshospitalet, and University of Copenhagen, Blegdamsvej 9 , 2100 Copenhagen, Denmark

${ }^{\mathrm{b}}$ Department of Psychiatry, BIOARABA, Hospital Universitario de Alava, UPVIEHU. CIBERSAM, Vitoria, Spain

'Department of Mental Health and Sensory Organs, University of Siena School of Medicine, Siena, Italy

${ }^{\mathrm{d}}$ Department of Psychiatry, Psychotherapy and Psychosomatics, Vivantes Hospital am Urban and Vivantes

Hospital im Friedrichshain/Charite Medicine Berlin and University of Cologne, Germany

e Department of Psychiatry, Psychosomatic Medicine and Psychotherapy, University Hospital Frankfurt,

Frankfurt am Main, Germany

${ }^{f}$ Department of Psychiatry, Dokuz Eylül University, Izmir, Turkey

gUniversité de Paris and INSERM UMRS 1144, Paris, France

* Correspondence to: Psychiatric Center Copenhagen, Department O, Rigshospitalet, Blegdamsvej 9, 2100 Copenhagen, Denmark.
E-mail address: lars.vedel.kessing@regionh.dk (L.V. Kessing). 
h Department of Psychiatry, Service Hospitalo-Universitaire, GHU Paris Psychiatrie \& Neuroscience, Paris, France

'Department of Psychiatry and Psychotherapy, University Hospital Carl Gustav Carus, TU Dresden, Dresden, Germany

jDepartment of Psychiatry and Psychotherapeutic Medicine, Medical University of Graz, Graz, Austria

${ }^{k}$ Department of Psychiatry, St Olav University Hospital \& Department of Mental Health, Norwegian

University of Science and Technology - NTNU, Trondheim, Norway

'Department of Psychiatry, University of Oxford and Oxford Health NHS Foundation Trust, Oxford, United Kingdom

$\mathrm{m}$ Institute of Neuroscience, Newcastle University, Newcastle, United Kingdom

${ }^{n}$ Department of Genetic Epidemiology in Psychiatry, Central Institute of Mental Health, Medical Faculty

Mannheim, University of Heidelberg, Mannheim, Germany

${ }^{\circ}$ Department of Psychiatry and Neurochemistry, University of Gothenburg, Gothenburg, Sweden

p Section of Psychiatry, Department of Medical Sciences and Public Health, University of Cagliari,

Cagliari, Italia

"Department of Pharmacology, Dalhousie University, Halifax, NS, Canada

rOsakidetza, Basque Health Service. Bioaraba, Health Research Institute, University of the Basque

Country, UPV/EHU, Spain

${ }^{s}$ Psychology Clinic of East Anglia. 68 Bishopgate, NR1 4AA, Norwich, United Kingdom

${ }^{\mathrm{t}}$ NORMENT Centre, Division of Mental Health and Addiction, Oslo University Hospital \& Institute of

Clinical Medicine, University of Oslo, Oslo, Norway

u Department of Psychiatry, University Hospital Carl Gustav Carus at the Technische Universität Dresden,

Dresden, Germany

${ }^{\vee}$ Department of Psychiatry, Amsterdam UMC, Vrije Universiteit, Amsterdam, the Netherlands

${ }^{\mathrm{w}}$ Aalborg University Hospital, Psychiatry, Aalborg, Denmark

×Department of Clinical Medicine, Aalborg University, Aalborg, Denmark

${ }^{y}$ Institute of Psychiatric Phenomics and Genomics (IPPG), University Hospital, LMU Munich, Germany

${ }^{z}$ Department of Psychiatry, Dalhousie University, Halifax, NS, Canada

aa National Institute of Mental Health, Klecany, Czech Republic

${ }^{\mathrm{ab}}$ Department of Psychiatry and Department of Obstetrics, Gynecology and Reproductive Science, Icahn

School of Medicine and Mount Sinai, New York, USA

ac Department of Psychiatry, Erasmus Medical Center, Rotterdam, the Netherlands

ad Bipolar and Depressive Disorders Unit, Hospital Clinic, Institute of Neuroscience, University of

Barcelona, IDIBAPS, CIBERSAM, Barcelona, Catalonia, Spain

Received 26 November 2020; accepted 18 January 2021

Available online $x x x$

\section{KEYWORDS}

Bipolar disorder;DSM5;ICD-11; Validity of diagnosis;Diagnostic delay;Delayed early intervention

\begin{abstract}
This narrative review summarizes and discusses the implications of the Diagnostic and Statistical Manual of Mental Disorders (DSM)- 5 and the upcoming International Classification of Diseases (ICD)-11 classification systems on the prevalence of bipolar disorder and on the validity of the DSM-5 diagnosis of bipolar disorder according to the Robin and Guze criteria of diagnostic validity. Here we review and discuss current data on the prevalence of bipolar disorder diagnosed according to DSM-5 versus DSM-IV, and data on characteristics of bipolar disorder in the two diagnostic systems in relation to extended Robin and Guze criteria: 1) clinical presentation, 2) associations with para-clinical data such as brain imaging and blood-based biomarkers, 3) delimitation from other disorders, 4) associations with family history / genetics, 5) prognosis and long-term follow-up, and 6) treatment effects. The review highlights that few studies have investigated consequences for the prevalence of the diagnosis of bipolar disorder and for the validity of the diagnosis. Findings from these studies suggest a substantial decrease in the point prevalence of a diagnosis of bipolar with DSM-5 compared with DSM-IV, ranging from 30-50\%, but a smaller decrease in the prevalence during lifetime, corresponding to a $6 \%$ reduction. It is concluded that it is likely that the use of DSM-5 and ICD-11 will result in diagnostic delay and delayed early intervention in bipolar disorder. Finally, we recommend areas for future research. (C) 2021 Elsevier B.V. and ECNP. All rights reserved.
\end{abstract}




\section{Introduction}

Sine qua none, mood abnormalities characterize mood disorders. Accordingly, in DSM-IV (American Psychiatric Association, 1994) and ICD-10 (World Health Organization, 1992) elevated, expansive or irritable mood is required as the only cardinal symptom (criterion A) for a hypomanic/manic episode. In 2013 DSM-5 was published requiring increased energy or activity as a criterion A alongside mood disturbances to diagnose hypomania/mania (American Psychiatric Association, 2013). The intention with the modification of criterion A was to improve specificity of the diagnosis of hypomania/mania, and consequently of bipolar disorder (Calabrese et al., 2017). The International Classification of Diseases (ICD) will likely follow in the footsteps of the DSM definitions. The latest online released version of the ICD11 , like DSM-5, includes increased energy or activity as criterion A alongside mood abnormalities (Angst et al., 2020; Reed et al., 2019; Severus and Bauer, 2020). These changes made in the classification system have consequences both for clinical practice as well as for research. The present narrative review summaries and discusses the implications of the DSM-5 and the upcoming ICD-11 diagnostic criteria for bipolar disorder in relation to 1) the prevalence of bipolar disorder and 2) the validity of the diagnosis of bipolar disorder according to extended Robin and Guze criteria of diagnostic validity (Robins and Guze, 1970). We would query the clinical or epidemiological usefulness of substantial changes in diagnostic criteria that are inadequately justified by reliable advances in clinical or mechanistic understanding of the disorder. Hence, this review will not address all the changes introduced in DSM-5 as compared to DSM-IV regarding affective disorders, which include creating an independent chapter for bipolar disorders, accepting antidepressant-induced manic or hypomanic switch as part of the condition under certain circumstances (Valentí et al., 2012), and re-defining mixed states as a specifier rather than an episode subtype (Pacchiarotti et al., 2020). Moreover, this review does not constitute a totally alternative proposal for the diagnostic classification of bipolar disorders (Ghaemi et al., 2008), and potential additions to forthcoming versions of DSM-5, such as the inclusion of new specifiers (predominant polarity, early onset, cognitive impairment, and others) (Pallaskorpi et al., 2019; Vieta, 2014) are not discussed.

\section{Results}

\subsection{Background for changes from DSM-IV to DSM-5 diagnosis of bipolar disorder}

Initially when Kraepelin described mania and depression, he identified three core domains - mood, cognition and motor activity - without ascribing primacy to any of these three domains (Fredskild et al., 2019). It was only later with the appearance of the DSM that mood was highlighted as the most important domain (Fredskild et al., 2019). The modification of the criterion A in DSM-5, requiring the presence of increased energy or activity for the diagnosis of mania and hypomania and, therefore, for the diagnosis of bipo- lar disorders, was likely based on the data from the BRIDGE study (Angst et al., 2011), which showed that increased activity was one of the most common symptoms in individuals with bipolar disorder. Kraepelin's original description included change in motor activation as a core domain of mania and depression together with changes in mood and cognition. This seminal observation has been complemented by a few longitudinal data showing that episode forecasting highly relies on changes in energy levels as an important predictor of recurrences of episodes (Ortiz et al., 2018). Further, increased activation levels have been found to predict bipolar disorder diagnosis in a sample of first psychotic episodes (Arrasate et al., 2014). A systematic review of factor analytic studies provide fairly consistent evidence that mood and activation represent a distinct dimension of bipolar disorder and possibly of the construct structure of BD especially BD-I- is more often characterized by an activation factor than a mood factor (Scott et al., 2017). The reasons why the DSM project originally omitted a motor criterion as part of the A criterion are unclear and a few studies have now investigated the impact of the modification to DSM-5 criterion A for the diagnosis of hypomanic/manic episodes.

\subsection{The prevalence of bipolar disorder according to DSM-5 versus DSM-IV or ICD-10 criteria}

The modified DSM-5 criteria impact the prevalence of hypomanic/manic episodes. The STEP-BD study (MachadoVieira et al., 2017) found that applying DSM-5 criteria reduced the identified number of hypomanic/manic episodes by $48 \%$ compared with DSM-IV criterion A. Fredskild et al. (2019) found a 34\% reduction in the number of individuals with bipolar disorder experiencing a hypomanic/manic episode during follow up when DSM-5 criterion A was applied. Notably the two mentioned studies included also populations with bipolar disorder with a more chronic course. An ongoing longitudinal study of 387 patients with bipolar disorder newly diagnosed with ICD-10 reported a reduction of $60 \%$ in the prevalence of hypomania/mania at the first visit and reduction of $50 \%$ in the number of subjects who experience a hypomanic/manic visit during follow-up when applying DSM-5 criteria (Fredskild et al., 2020). In the two latter studies including patients with an ICD-10 bipolar diagnosis, the probability of a patient receiving a DSM- 5 diagnosis of bipolar disorder increased with the number of clinical visits (Fredskild et al., 2019, 2020). Further, empirical data show that DSM-5 capture fewer hypomanic/manic episodes with irritable mood than the DSM-IV because irritable mood is less often associated with increased energy/activity in contrast to elevated mood (Fredskild et al., 2020) and so will not meet the DSM-5 A criterion.

Differences between DSM-IV and DSM-5 are smaller regarding the lifetime prevalence of bipolar disorder. The U.K. Bipolar Disorder Research Network (BDRN) study (GordonSmith et al., 2017) found that up to $94 \%$ of patients with a lifetime diagnosis of DSM-IV bipolar disorder also met lifetime DSM-5 criteria for bipolar disorder. Similarly, reanalyses of data from the Zurich cohort showed a small reduction in the lifetime diagnosis of bipolar disorder with ICD-11 compared with ICD-10 (from 31 to 29 patients, corresponding to 6\%) (Angst et al., 2020). These findings are intu- 
itively reliable because the broad population of newly diagnosed patients are more heterogenous by nature with fewer patients fulfilling the narrower DSM-5 criteria for bipolar disorder than among patients with more progressed and chronic disorders.

Together, studies report a substantial decrease in the number of patients that fulfill the new criteria for bipolar disorder. Patients with an irritable mood will less often be diagnosed as bipolar according to DSM-5 because patients with an irritable mood do not usually have increased energy/activity.

\subsection{The validity of the DSM-5 diagnosis of bipolar disorder}

Few data are available on the validity of the DSM-5 diagnosis of bipolar disorder, but we find it important to highlight these knowledge gaps. Validity of the DSM-5 diagnosis of bipolar disorder is described and discussed according to the Robin and Guze criteria of diagnostic validity (Robins and Guze, 1970), moderated to including also treatment effects as a sixth criterion, also concurrent with the later endophenotype concept (Gottesman and Gould, 2003) and extended criteria suggestions (Kendler and Neale, 2010). The rationale for the Robin and Guze criteria was to develop criteria distinguishing between various psychiatric disorders and aiming for a valid psychiatric classification system (Robins and Guze, 1970). Characteristics of bipolar disorder diagnosed according to DSM-5 versus DSM-IV within the sixth areas according to the extended Robin and Guze criteria (Robins and Guze, 1970) are listed below.

\subsubsection{Clinical presentation according to DSM-5 versus DSM-IV}

Patients with bipolar disorder defined according to DSM5 criteria compared to patients with bipolar disorder defined according to DSM-IV criteria are characterized by more severe manic episodes according to scores on the Young Mania Rating Scale (Fredskild et al., 2019, 2020), more comorbidity with obsessive-compulsive disorder (MachadoVieira et al., 2017) and a higher annual income (MachadoVieira et al., 2017). No differences have been found in sex (Fredskild et al., 2019, 2020; Machado-Vieira et al., 2017), age (Fredskild et al., 2019, 2020; Machado-Vieira et al., 2017), family history (Fredskild et al., 2020; MachadoVieira et al., 2017), bipolar disorder subtype I or II (Fredskild et al., 2020; Machado-Vieira et al., 2017), number of previous hospitalizations (Fredskild et al., 2020), comorbid panic disorder, posttraumatic stress disorder, social phobia, substance use (Machado-Vieira et al., 2017), suicide attempts (Machado-Vieira et al., 2017) or use of medication (Machado-Vieira et al., 2017).

\subsubsection{Associations of the phenotype with para-clinical data}

Para-clinical data may include blood-based data, brain imaging and Electronic Ecological Momentary Assessment (EMA), such as smartphones that are particularly useful for continuous monitoring of daily activity levels in adults (Faurholt-Jepsen et al., 2020; Stanislaus et al., 2020) and young patients with bipolar disorder (Melbye et al., 2020).
Due to its potentially higher specificity, the DSM- 5 diagnosis of bipolar disorder (see point 3 below) may be associated with a higher chance of identifying para-clinical biomarkers but currently we are not aware of any published data to support this.

\subsubsection{Delimitation from other disorders}

No data are available comparing the delimitation of bipolar disorder from schizophrenia, schizoaffective disorder, depressive disorder, personality disorders or other disorders when using the DSM-5 versus the DSM-IV or ICD-10 criteria. Nevertheless, in a sample of patients with first-episode psychosis, activation and manic dimensions according to scores on the Young Mania Rating Scale (Young et al., 1978) discriminated between patients with bipolar disorder and other psychoses (Arrasate et al., 2014). Activation predicted a bipolar diagnosis at 5 years (odds ratio $=1.383$; $95 \%$ confidence interval, $1.205-1.587 ; P=0.001$ ) as the only dimension, and showed higher levels of sensitivity $(86.2 \%)$, specificity $(71.7 \%)$, positive $(57.8 \%)$ and negative predictive value $(90.5 \%)$ than the manic dimension (Arrasate et al., 2014). It should nevertheless be noted that the manic dimension was broadly defined besides including elevated mood also included increased sexual interest and reduced sleep (Arrasate et al., 2014). As previously noted, the additional activity criterion A in DSM-5 probably increases specificity at the expense of sensitivity, but is unclear whether the DSM-5 optimize the balance of sensitivity and specificity from a clinical perspective (Calabrese et al., 2017).

\subsubsection{Pathogenesis - associations to family} history/genetics and environmental stressors Due to the possibly higher specificity there might likely be a higher chance with DSM-5 criteria of identifying familial loading for bipolar disorder, but the current data does not support this, finding no differences in first or secondgeneration family history of bipolar disorder in the DSM5 defined group compared with the DSM-IV defined group of patients (Fredskild et al., 2020; Machado-Vieira et al., 2017).

\subsubsection{Prognosis - long-term follow-up}

In the study including patients with newly diagnosed ICD10 bipolar disorder (Fredskild, 2020) fewer patients, i.e. $40 \%$, fulfilled DSM-5 criteria for bipolar disorder than in the two studies including patients with more progressed or chronic disorders, in which 52\% (Machado-Vieira et al., 2017) and 66\% (Fredskild et al., 2019) fulfilled DSM-5 criteria for bipolar disorder. In the two studies with lifetime diagnoses as much as $94 \%$ of patients in each study fulfilled a lifetime diagnosis of DSM-5 bipolar disorder (Angst et al., 2020; Gordon-Smith et al., 2017). These findings are intuitively reliable as the broad population of newly diagnosed patients are more heterogenous by nature with fewer patients fulfilling the narrower DSM-5 criteria for bipolar disorder than among patients with more progressed and chronic disorders. In addition, among patients with an ICD-10 diagnosis of bipolar disorder the probability of fulfilling criteria for a DSM-5 diagnosis of bipolar disorder was shown to increase with the number of clinical visits (Fredskild et al., 2019, 2020) implying that the threshold for a DSM-5 diagnosis of bipolar disorder is reached later in the course 
of the illness. A corollary of these findings is that DSM-5 might not capture less severe bipolar disorder, especially during the early course of illness. This may cause increased diagnostic delay (Baldessarini et al., 2007; Dagani et al., 2017), because patients may not fulfill criteria for bipolar disorder until later stages of the illness, resulting in delayed early intervention (Kessing, 2019; Kessing et al., 2013; Kessing et al., 2014). Several studies conducted in many countries worldwide have reported delays in DSM-IV and ICD-10 diagnosis for bipolar disorder as well as frequent misdiagnoses with other disorders. One of them conducted in 30 European countries for example indicated that, on average, a bipolar disorder patient was expected to wait for 5.7 years for a correct diagnosis from the first onset of symptoms (Morselli and Elgie, 2003). A substantial proportion of patients, constituting more than $40 \%$, initially present with prodromal syndromes such as transient psychosis, reaction to stress/adjustment disorder or mental and behavioural disorder due to psychoactive substance use before they get an ICD-10 diagnosis of bipolar disorder later on (Kessing, 2005). Especially younger but also female patients are at increased risk of delay of the diagnosis of bipolar disorder (Kessing, 2005). If less severe bipolar disorders may be overlooked with the DSM-5 criteria one may expect even longer delays in correct diagnosis for bipolar disorder. This is a critical issue since early intervention is a key tool to prevent further complications, cognitive, and functional decline (Carvalho et al., 2020; Kessing and Andersen, 2017; Vieta, 2015; Vieta et al., 2018). Further, we have no good definition for at risk/prodromal bipolar disorder emphasizing the challenges with the DSM-5 classification system, delaying early recognition and intervention. Alternatively, the proportion of patients diagnosed with the DSM- 5 categories of "other specified bipolar and related disorders" and "unspecified bipolar disorder" may increase, with the latter adding to the unspecified or "gray" diagnostic zone.

\subsubsection{Treatment effects}

Ultimately, the clinical utility of any diagnostic system is to inform the choice of right treatment. The effects of lithium and other mood stabilizing agent may be different in bipolar disorder as defined by DSM 5 vs. DSM-IV as their effects on behavioral disturbances (activation/energy levels) differ. Using the DSM-5 criteria, there might be larger treatment effects with lithium, which may show greater efficacy in bipolar disorder type I, but we have no data to support this other than the fact that lithium is more often prescribed in bipolar I disorder than in bipolar II (Grande et al., 2013; Vieta et al., 2011; Vinberg et al., 2017). In fact, core features of lithium responsive bipolar disorder do not include energy/activation among the most reliable predictors (Alda, 2015). Further, an out-of-sample lithium response prediction was not significantly informed by disorder subtype I in a recent machine learning study in a large sample of direct interview-based clinical data from lithium-treated DSM-IV bipolar disorder patients (Nunes et al., 2020).

On the other hand, as at least the short term-prevalence of mania is decreased when using DSM-5 criteria, there is a considerable number of patients which will not be given lithium or other effective anti-manic substances. Whether this relates to better or worse outcome must be shown in future. It can be argued that, as lithium has proven prophy- lactic effects, it is unlikely that the care of patients suffering from mental disorders will benefit. However, there is a lack of precision in prescribing (identification of lithium responders is still predominantly based on trial and error), so refining clinical phenotypes may prove to have clinical utility (Scott et al., 2018). In addition, there might be less effects of lamotrigine and other drugs mainly prescribed for bipolar disorder type II.

\section{Discussion}

\subsection{Implications and knowledge gaps in relation to DSM-5 defined bipolar disorder and recommendations of areas for future research}

The present review highlights that implications of the DSM- 5 diagnostic system are poorly known with few studies investigating consequences for the prevalence of the diagnosis of bipolar disorder and for the validity of the diagnosis according to the Robin and Guze criteria.

\subsection{Implications}

It is likely but poorly investigated so far whether the use of DSM-5 and ICD-11 will result in diagnostic delay and delayed early intervention. This would be a concern, since early detection and intervention is regarded as crucial to improve long term outcome in bipolar disorder (Carvalho et al., 2020; Kessing, 2019; Kessing and Andersen, 2017; Kessing et al., 2013; Kessing et al., 2014; Vieta, 2015; Vieta et al., 2018). The need for a common international language has fostered the convergence between DSM-5 and ICD-11, irrespective of their internal and external validity (Stein et al., 2020). Hence, conservative attitudes and fear of accusations of broadening too much the borders of the diagnosis of bipolar disorder have resulted in misinterpretations of the evidence base (the BRIDGE study does not imply that increased activity should be used as a requirement for the diagnosis (Angst, 2013)) and neglect of innovative proposals, which should be addressed in further editions of the DSM (Vieta, 2016). In fact these data more suggest increased activity as an OR than an AND addition to criterion A for the diagnosis of hypomanic/manic episodes (Angst, 2013).

\subsection{Knowledge gaps}

Can we identify the patients with bipolar disorder who meet the DSM-IV or ICD-10 diagnostic criteria but who may no longer be diagnosed with bipolar disorder using the DSM5 criteria or whose diagnosis may be delayed until A criterion symptoms become established? Current data do not tell us which patients will be diagnosed at a later stage, but these may comprise patients with bipolar disorder, type II, "other specified bipolar and related disorders" according to DSM-5 as well as patients experiencing recurrent depressive episodes, who do not fulfill DSM-5 criteria but DSM-IV or ICD10 for hypomania or mania. This may result in either suboptimal guideline-driven treatments, e.g. as antidepressant 
have shown small effects on depressive episodes in patients with bipolar disorder, or non-guideline-based treatments as clinicians could consider patients as having bipolar disorder, but not yet fulfilling full diagnostic criteria. The latter may result in a poorer diagnostic reliability as well as a less reliable epidemiological data. On the other hand, at least in some cases (ADHD, personality syndromes/disorders, affective dysregulation, tighter diagnostic criteria as those introduced with DSM-5 might spare patients from lifelong treatment with lithium or antipsychotics that would not help them (Severus and Bauer, 2013).

\subsection{Areas for future research}

The DSM-5 criteria for hypomania/mania requiring increased energy or activity as an additional criterion $\mathrm{A}$ alongside mood disturbances ( American Psychiatric Association, 2013) were introduced in 2013 without compelling evidence or thorough consideration of possible implications. Subsequently the four mentioned published studies and one ongoing study (Angst et al., 2020; Fredskild et al., 2019, 2020; Gordon-Smith et al., 2017; Machado-Vieira et al., 2017) have investigated the prevalence of bipolar disorder according to DSM-5 versus DSM-IV or ICD-10 criteria, but further studies are greatly needed. Thus, further studies are needed within the sixth mentioned validation areas: 1) Clinical presentation according to DSM-5 versus DSM-IV/ICD-10, 2) Associations of the phenotype with paraclinical data such as brain imaging and blood-based data, 3) Delimitation from other disorders, specifically schizophrenia, schizoaffective disorder, depressive disorder, personality disorders, 4) Pathogenesis - associations to family history / genetics and environmental stressors, 5) Prognosis, specifically in relation to implications for diagnostic delay and early intervention as well as long-term diagnostic stability (Kessing, 2005; Kessing et al., 2015; Laursen et al., 2020), 6) Medical treatment effects of lithium and other mood stabilizers. At some point, the official classification systems will need to incorporate information from sources other than symptoms, and this may come not only from genetic, neuroimaging, and biomarker data, but also from the increasing use of digital markers, in the frame of so-called precision psychiatry (Manchia et al., 2020; Salagre et al., 2018). This however requires the identification of specific neurobiological mechanisms that define mental disorders by their pathophysiology rather than their symptoms; the jury is still out whether this will adhere to current diagnostic boundaries.

\section{Conclusion}

The review highlights that few studies have investigated consequences for the prevalence of the diagnosis of bipolar disorder and for the validity of the diagnosis. Findings from these studies suggest a substantial decrease in the point prevalence of a diagnosis of bipolar with DSM-5 compared with DSM-IV, ranging from $30-50 \%$, but a smaller decrease in the prevalence during lifetime, corresponding to a $6 \%$ reduction. It is concluded that it is likely that the use of DSM-5 and ICD-11 will result in diagnostic delay and delayed early intervention in bipolar disorder. Specific analyses of the reliability (Freedman et al., 2013) and validity of the DSM and ICD criteria, and an evidence-based, data driven approach to every proposed change in the criteria are urgently needed.

\section{Role of the funding source}

The ECNP Bipolar Disorders Network is supported by an unrestricted grant from the ECNP.

\section{Contributors}

LVK drafted the first version of the manuscript together with EV. All other authors contributed substantially during iterative subsequent revisions and accepted the final version of the manuscript.

\section{Conflict of interest}

LVK has received consultancy fees from Lundbeck and Teva in the past three years.

$A B$ has received research grants from. Lundbeck, Otsuka Pharmaceuticals and Janssen for investigator initiated clinical trials and received speaking fees from Bristol-Myers Squibb, Astra Zeneca, Janssen, Lundbeck and Otsuka Pharmaceuticals,

BE has received consultancy fees from Sanofi Aventis in the past three years.

GMG is a NIHR Emeritus Senior Investigator and Medical Director at P1vital products, holds shares in P1vital and P1Vital products and has served as consultant, advisor or CME speaker in the last 3 years for Beckley Psytech, Clerkenwell Health, Compass pathways, Evapharma, Janssen, Lundbeck, Medscape, Novartis, P1Vital, Sage, Servier. The views expressed are those of the author(s) and not necessarily those of the NHS, the NIHR or the Department of Health.

MM has received advisory board honorarium by Angelini.

$M L$ has received lecture honoraria from Lundbeck pharmaceutical in the past three years.

OAA is a consultant to HealthLytix, and has received speaker's honorarium from Lundbeck and Synovion.

REN has received research grants from $\mathrm{H}$. Lundbeck and Otsuka Pharmaceuticals for clinical trials, received speaking fees from Bristol-Myers Squibb, Astra Zeneca, Janssen \& Cilag, Lundbeck, Servier, Otsuka Pharmaceuticals, Teva A/S, and Eli Lilly and has acted as advisor to Astra Zeneca, Eli Lilly, Lundbeck, Otsuka Pharmaceuticals, Takeda, and Medivir, and has acted as investigator for Janssen-Cilag, Lundbeck, Boehringer, Compass and Sage.

EV has received grants and served as consultant, advisor or CME speaker for the following entities (unrelated to the present work): AB-Biotics, Abbott, Allergan, Angelini, Dainippon Sumitomo Pharma, Ferrer, Gedeon Richter, GH Research, Janssen, Lundbeck, Otsuka, Sage, Sanofi-Aventis, and Takeda.

RWL has received research grant from Glaxo Smith Kline, honoraria for lecturing from Pfizer, Glaxo Smith Kline, Eli 
Lilly, Astra-Zeneca, Bristol-Myers Squibb, Janssen Cilag, Lundbeck, Otsuka, Servier and honoraria from advisory board activity from Glaxo Smith Kline, Eli Lilly, AstraZeneca, Bristol-Myers Squibb, Janssen Cilag, Sunovion and Sage.

\section{The remaining authors report no conflicts of interest.}

\section{Acknowledgment}

None.

\section{References}

Alda, M., 2015. Lithium in the treatment of bipolar disorder: pharmacology and pharmacogenetics. Mol. Psychiatry 20, 661-670.

Angst, J., 2013. Bipolar disorders in DSM-5: strengths, problems and perspectives. Int. J. Bipolar Disord. 1, 12.

American Psychiatric Association, A. P., 2013. Diagnostic and Statistical Manual of Mental Disorders, Fifth ed. American Psychiatric Association, Arlington, VA.

American Psychiatric Association., A. P., 1994. Diagnostic and Statistical Manual of Mental Disorders: DSM-IV, 4th ed. American Psychiatric Association, Washington, DC, USA.

Angst, J., Ajdacic-Gross, V., Rössler, W., 2020. Bipolar disorders in ICD-11: current status and strengths. Int. J. Bipolar Disord. 8, 3.

Angst, J., Azorin, J.M., Bowden, C.L., Perugi, G., Vieta, E., Gamma, A., Young, A.H., 2011. Prevalence and characteristics of undiagnosed bipolar disorders in patients with a major depressive episode: the BRIDGE study. Arch. Gen. Psychiatry 68, 791-798.

Arrasate, M., González-Ortega, I., Alberich, S., Gutierrez, M., Martínez-Cengotitabengoa, M., Mosquera, F., Cruz, N., González-Torres, M.A., Henry, C., González-Pinto, A., 2014. Affective dimensions as a diagnostic tool for bipolar disorder in first psychotic episodes. Eur. Psychiatry 29, 424-430.

Baldessarini, R.J., Tondo, L., Baethge, C.J., Lepri, B., Bratti, I.M., 2007. Effects of treatment latency on response to maintenance treatment in manic-depressive disorders. Bipolar Disord. 9, 386-393.

Calabrese, J.R., Gao, K., Sachs, G., 2017. Diagnosing mania in the age of DSM-5. Am. J. Psychiatry 174, 8-10.

Carvalho, A.F., Firth, J., Vieta, E., 2020. Bipolar disorder. N. Engl. J. Med. 383, 58-66.

Dagani, J., Signorini, G., Nielssen, O., Bani, M., Pastore, A., Girolamo, G., Large, M., 2017. Meta-analysis of the interval between the onset and management of bipolar disorder. Can. J. Psychiatry $62,247-258$.

Faurholt-Jepsen, M., Busk, J., Vinberg, M., Christensen, E.M., Helgabórarinsdóttir, Frost, M., Bardram, J.E., Kessing, L.V, 2020. Daily mobility patterns in patients with bipolar disorder and healthy individuals. J. Affect. Disord. 278, 413-422.

Fredskild, M.U., Stanislaus, S., Coello, K., Melbye, S.A., Kjærstad, H.L., Sletved, K.S.O., Suppe, T., Vinberg, M., Kessing, L.V., 2020. Impact of modification to DSM-5 criterion A for hypoma$\mathrm{nia} /$ mania in newly diagnosed/first episode bipolar patients findings from the BIO study. Int. J. Bipolar Disord., in press.

Fredskild, M.U., Mintz, J., Frye, M.A., McElroy, S.L., Nolen, W.A., Kupka, R., Grunze, H., Keck Jr., P.E., Post, R.M., Kessing, L.V., Suppes, T, 2019. Adding increased energy or activity to criterion (A) of the DSM-5 definition of hypomania and mania: effect on the diagnoses of 907 patients from the bipolar collaborative network. J. Clin. Psychiatry 80 (6).

Freedman, R., Lewis, D.A., Michels, R., Pine, D.S., Schultz, S.K., Tamminga, C.A., Gabbard, G.O., Gau, S.S., Javitt, D.C., Oquendo, M.A., Shrout, P.E., Vieta, E., Yager, J., 2013. The ini- tial field trials of DSM-5: new blooms and old thorns. Am. J. Psychiatry 170, 1-5.

Ghaemi, S.N., Bauer, M., Cassidy, F., Malhi, G.S., Mitchell, P., Phelps, J., Vieta, E., Youngstrom, E., 2008. Diagnostic guidelines for bipolar disorder: a summary of the international society for bipolar disorders diagnostic guidelines task force report. Bipolar Disord. 10, 117-128.

Gordon-Smith, K., Jones, L.A., Forty, L., Craddock, N., Jones, I., 2017. Changes to the diagnostic criteria for bipolar disorder in DSM-5 make little difference to lifetime diagnosis: findings from the U.K. bipolar disorder research network (BDRN) Study. Am. J. Psychiatry 174, 803.

Gottesman, I.I., Gould, T.D., 2003. The endophenotype concept in psychiatry: etymology and strategic intentions. Am. J. Psychiatry 160, 636-645.

Grande, I., de Arce, R., Jiménez-Arriero, M., Lorenzo, F.G., Valverde, J.I., Balanzá-Martínez, V., Zaragoza, S., Cobaleda, S., Vieta, E., 2013. Patterns of pharmacological maintenance treatment in a community mental health services bipolar disorder cohort study (SIN-DEPRES). Int. J. Neuropsychopharmacol. 16, 513-523.

Kendler, K.S., Neale, M.C., 2010. Endophenotype: a conceptual analysis. Mol. Psychiatry 15, 789-797.

Kessing, L.V., 2005. Diagnostic stability in bipolar disorder in clinical practise as according to ICD-10. J. Affect. Disord. 85, 293-299.

Kessing, L.V., 2019. What is early intervention in bipolar disorder? Recommendation of a pragmatic way focusing on early intervention in patients with newly diagnosed bipolar disorder. Bipolar Disord. 21, 168-169.

Kessing, L.V., Andersen, P.K., 2017. Evidence for clinical progression of unipolar and bipolar disorders. Acta Psychiatr. Scand. 135, 51-64.

Kessing, L.V., Hansen, H.V., Hvenegaard, A., Christensen, E.M., Dam, H., Gluud, C., Wetterslev, J., 2013. Treatment in a specialised out-patient mood disorder clinic v. standard out-patient treatment in the early course of bipolar disorder: randomised clinical trial. Br. J. Psychiatry 202, 212-219.

Kessing, L.V., Vradi, E., Andersen, P.K., 2014. Starting lithium prophylaxis early v. late in bipolar disorder. Br. J. Psychiatry 205, 214-220.

Kessing, L.V., Vradi, E., Kragh, A.P., 2015. Diagnostic stability in pediatric bipolar disorder. J. Affect. Disord. 172, 417-421.

Laursen, M.F., Licht, R.W., Correll, C.U., Kallehauge, T., Christensen, A.E., Rodrigo-Domingo, M., Nielsen, R.E., 2020. Diagnostic stability in children and adolescents with bipolar disorder, a nationwide register-based study. Int. J. Bipolar Disord. 8, 14.

Machado-Vieira, R., Luckenbaugh, D.A., Ballard, E.D., Henter, I.D., Tohen, M., Suppes, T., Zarate Jr., C.A., 2017. Increased activity or energy as a primary criterion for the diagnosis of bipolar mania in DSM-5: findings from the STEP-BD study. Am. J. Psychiatry 174, 70-76.

Manchia, M., Vieta, E., Smeland, O.B., Altimus, C., Bechdolf, A., Bellivier, F., Bergink, V., Fagiolini, A., Geddes, J.R., Hajek, T., Henry, C., Kupka, R., Lagerberg, T.V., Licht, R.W., MartinezCengotitabengoa, M., Morken, G., Nielsen, R.E., Pinto, A.G., Reif, A., Rietschel, M., Ritter, P., Schulze, T.G., Scott, J., Severus, E., Yildiz, A., Kessing, L.V., Bauer, M., Goodwin, G.M., Andreassen, O.A., 2020. Translating big data to better treatment in bipolar disorder - a manifesto for coordinated action. Eur. Neuropsychopharmacol. 36, 121-136.

Melbye, S.A., Stanislaus, S., Vinberg, M., Frost, M., Bardram, J.E., Sletved, K., Coello, K., Kjærstad, H.L., Christensen, E.M., Faurholt-Jepsen, M., Kessing, L.V., 2020. Mood, activity, and sleep measured via daily smartphone-based self-monitoring in young patients with newly diagnosed bipolar disorder, their unaffected relatives and healthy control individuals. Eur. Child Adolesc. Psychiatry. 
Morselli, P.L., Elgie, R., 2003. GAMIAN-Europe/BEAM survey I-global analysis of a patient questionnaire circulated to 3450 members of 12 European advocacy groups operating in the field of mood disorders. Bipolar Disord. 5, 265-278.

Nunes, A., Ardau, R., Berghöfer, A., Bocchetta, A., Chillotti, C., Deiana, V., Garnham, J., Grof, E., Hajek, T., Manchia, M., Müller-Oerlinghausen, B., Pinna, M., Pisanu, C., O’Donovan, C., Severino, G., Slaney, C., Suwalska, A., Zvolsky, P., Cervantes, P., Del Zompo, M., Grof, P., Rybakowski, J., Tondo, L., Trappenberg, T., Alda, M., 2020. Prediction of lithium response using clinical data. Acta Psychiatr. Scand. 141, 131-141.

Ortiz, A., Bradler, K., Hintze, A., 2018. Episode forecasting in bipolar disorder: is energy better than mood? Bipolar Disord..

Pacchiarotti, I., Kotzalidis, G.D., Murru, A., Mazzarini, L., Rapinesi, C., Valentí, M., Anmella, G., Gomes-da-Costa, S., Gimenez, A., Llach, C., Perugi, G., Vieta, E., Verdolini, N., 2020. Mixed features in depression: the unmet needs of diagnostic and statistical manual of mental disorders fifth edition. Psychiatr. Clin. N. Am. 43, 59-68.

Pallaskorpi, S., Suominen, K., Rosenström, T., Mantere, O., Arvilommi, P., Valtonen, H., Leppämäki, S., García-Estela, A., Grande, I., Colom, F., Vieta, E., Isometsä, E., 2019. Predominant polarity in bipolar I and II disorders: a five-year follow-up study. J. Affect. Disord. 246, 806-813.

Reed, G.M., First, M.B., Kogan, C.S., Hyman, S.E., Gureje, O., Gaebel, W., Maj, M., Stein, D.J., Maercker, A., Tyrer, P., Claudino, A., Garralda, E., Salvador-Carulla, L., Ray, R., Saunders, J.B., Dua, T., Poznyak, V., Medina-Mora, M.E., Pike, K.M., Ayuso-Mateos, J.L., Kanba, S., Keeley, J.W., Khoury, B., Krasnov, V.N., Kulygina, M., Lovell, A.M., de, Jesus, Mari, J., Maruta, T., Matsumoto, C., Rebello, T.J., Roberts, M.C., Robles, R., Sharan, P., Zhao, M., Jablensky, A., Udomratn, P., Rahimi-Movaghar, A., Rydelius, P.A., Bährer-Kohler, S., Watts, A.D., Saxena, S., 2019. Innovations and changes in the ICD-11 classification of mental, behavioural and neurodevelopmental disorders. World Psychiatry 18, 3-19.

Robins, E., Guze, S.B., 1970. Establishment of diagnostic validity in psychiatric illness: its application to schizophrenia. Am. J Psychiatry $126,983-987$.

Salagre, E., Dodd, S., Aedo, A., Rosa, A., Amoretti, S., Pinzon, J., Reinares, M., Berk, M., Kapczinski, F.P., Vieta, E., Grande, I., 2018. Toward precision psychiatry in bipolar disorder: staging 2.0. Front. Psychiatry 9, 641.

Scott, J., Etain, B., Bellivier, F., 2018. Can an integrated science approach to precision medicine research improve lithium treatment in bipolar disorders? Front. Psychiatry 9, 360.
Scott, J., Murray, G., Henry, C., Morken, G., Scott, E., Angst, J., Merikangas, K.R., Hickie, I.B., 2017. Activation in bipolar disorders: a systematic review. JAMA Psychiatry 74, 189-196.

Severus, E., Bauer, M., 2013. Diagnosing bipolar disorders in DSM-5. Int. J. Bipolar Disord. 1, 14.

Severus, E., Bauer, M., 2020. Diagnosing bipolar disorders: ICD-11 and beyond. Int. J. Bipolar Disord. 8, 4.

Stanislaus, S., Vinberg, M., Melbye, S., Frost, M., Busk, J., Bardram, J.E., Kessing, L.V., Faurholt-Jepsen, M., 2020. Smartphone-based activity measurements in patients with newly diagnosed bipolar disorder, unaffected relatives and control individuals. Int. J. Bipolar Disord. 8, 32.

Stein, D.J., Szatmari, P., Gaebel, W., Berk, M., Vieta, E., Maj, M., de Vries, Y.A., Roest, A.M., de Jonge, P., Maercker, A., Brewin, C.R., Pike, K.M., Grilo, C.M., Fineberg, N.A., Briken, P., Cohen-Kettenis, P.T., Reed, G.M., 2020. Mental, behavioral and neurodevelopmental disorders in the ICD-11: an international perspective on key changes and controversies. BMC Med. 18, 21.

Valentí, M., Pacchiarotti, I., Bonnín, C.M., Rosa, A.R., Popovic, D., Nivoli, A.M., Goikolea, J.M., Murru, A., Undurraga, J., Colom, F., Vieta, E., 2012. Risk factors for antidepressant-related switch to mania. J. Clin. Psychiatry 73, e271-e276.

Vieta, E., 2014. The bipolar maze: a roadmap through translational psychopathology. Acta Psychiatr. Scand. 129, 323-327.

Vieta, E., 2015. Staging and psychosocial early intervention in bipolar disorder. Lancet Psychiatry 2, 483-485.

Vieta, E., 2016. DSM-5.1. Acta Psychiatr. Scand. 134, 187-188.

Vieta, E., Blasco-Colmenares, E., Figueira, M.L., Langosch, J.M., Moreno-Manzanaro, M., Medina, E., 2011. Clinical management and burden of bipolar disorder: a multinational longitudinal study (WAVE-bd study). BMC Psychiatry 11, 58.

Vieta, E., Salagre, E., Grande, I., Carvalho, A.F., Fernandes, B.S., Berk, M., Birmaher, B., Tohen, M., Suppes, T., 2018. Early intervention in bipolar disorder. Am. J. Psychiatry 175, 411-426.

Vinberg, M., Mikkelsen, R.L., Kirkegaard, T., Christensen, E.M., Kessing, L.V., 2017. Differences in clinical presentation between bipolar I and II disorders in the early stages of bipolar disorder: a naturalistic study. J. Affect. Disord. 208, 521-527.

World Health Organization, W. H., 1992. The ICD-10 Classification of Mental and Behavioural Disorders: Clinical Descriptions and Diagnostic Guidelines. World Health Organisation, Geneva.

Young, R.C., Biggs, J.T., Ziegler, V.E., Meyer, D.A., 1978. A rating scale for mania: reliability, validity and sensitivity. Br. J. Psychiatry $133,429-435$. 